[CONTRIBUTION FROM THE HARRIMAN RESEARCH LABORATORY, ROOSEVEIT HOSPITAI, NEW YORK.]

\title{
STUDIES ON ENZYME ACTION. XII. THE ESTERASE AND LIPASE OF CASTOR BEANS.
}

By K. George FaLK aNd K. Sugrura.

Received September 28, 1914.

In a former paper, ${ }^{1}$ the results obtained in the extraction of a castor bean preparation by water and by solutions of different salts made it appear probable that substances showing different types of hydrolytic activity toward esters existed in castor beans. Greater activity, under certain fixed conditions, toward ethyl butyrate than toward triacetin was found associated with substances soluble in water, while greater activity toward triacetin than toward ethyl butyrate was found associated with a substance or with substances insoluble in water.

For the sake of a convenient terminology, the terms esterase and lipase will be used in this paper to represent these two types of hydrolytic action under certain definite conditions, esterase referring to the substance exhibiting the first action, lipase to the substance exhibiting the second. There is, however, no intention of establishing arbitrary differences between the two kinds of action. Undoubtedly the substance termed esterase hydrolyzes complex esters such as the fats, and the substance termed lipase hydrolyzes simple esters to a certain extent.

In this paper some experiments with the castor bean preparation on the activity toward triacetin in different salt solutions will be described; then the separation of the esterase and of a lipase from the castor bean preparation will be shown, together with a study of their hydrolytic actions under various conditions; and finally the analyses of the different preparations and the forms of combination. of the nitrogen in them will be given.

In all of the tests of hydrolytic actions which are given in this paper, the procedure was the same as that described in preceding papers. When the action of a given preparation was measured on ethyl butyrate, one cc. of the neutral ester was added to the stated amount of solution or mixture, while if the action on triacetin was studied, $0.5 \mathrm{cc}$. of this ester, practically neutral in reaction, was used. The mixtures were placed in the incubator at $38-40^{\circ}$ for 24 or $48 \mathrm{hrs}$. (or other time as stated) and then titrated with standard sodium hydroxide solution, approximately o.I $N$. At the same time, suitable blanks were run as usual and the final restults, which alone are given here, give the corrected values for the acid formed from each ester, in terms of cc. of o.I $N$ solution. The tests with ethyl butyrate are generally designated by $\mathrm{Et} \mathrm{Bu}$, with triacetin, by Triac.

The castor bean preparation used in these experiments was prepared

${ }^{1}$ IX paper of this series, ThIs JOURNAL, 35, I904 (1913). 
from a new lot of cold pressed castor beans. ${ }^{1}$ The shells were removed by hand, the kernels ground, extracted exhaustively with ether in a Soxhlet apparatus, dried in air and ground to pass through a 40 mesh sifter. Throughout this work, toluene was added to every solution and mixture, when extracting, filtering, or testing activities, to prevent bacterial growth.

A number of extraction experiments were carried out with the new preparation according to the method described in the IX Paper ${ }^{2}$ with the former preparation.

The results showed, in agreement with the former work, that $70 \%$ of the material showing activity toward ethyl butyrate and $33 \%(50 \%$ in the former work) of the material showing activity toward triacetin, could be extracted by water.

Some tests of the activity of the preparation in sodium chloride and sodium sulfate solutions toward triacetin are of interest. With $0.2 \mathrm{~g}$. castor bean preparation, $25 \mathrm{cc}$. solution, $0.5 \mathrm{cc}$. triacetin, and $24 \mathrm{hrs}$. tests, the following results were obtained:

Table I.-Action in AQueous Sodium Chloride and Sodium Sulfate Solutions of Castor Bean Preparation on Triacetin.

$\begin{array}{cccccccc} & 0 . & 0.02 M . & 0.05 M . & 0.1 M . & 0.1 M & 0.5 M . & 1 M . \\ \mathrm{NaCl} \ldots \ldots \ldots \ldots & \mathrm{I} .50 & \mathrm{I} .46 & 1.48 & \mathrm{I} .9 \mathrm{I} & 2.32 & \mathrm{I} .97 & \mathrm{I} .22 \\ \mathrm{Na}_{2} \mathrm{SO}_{4} \ldots \ldots \ldots \ldots \ldots & \mathrm{x} .55 & \ldots & \ldots & 3.5 \mathrm{I} & 4.32 & \ldots & \ldots\end{array}$

In the V Paper of this series ${ }^{3}$ it was shown that sodium chloride inhibited the action toward ethyl butyrate, the effect being distinct even at $0.005 \mathrm{M}$ and increasing with increase in concentration of the sodium chloride. Toward triacetin the activity increased with increasing salt concentration to a maximum at about $0.2 M$ and then decreased again. These results are strikingly similar to those obtained with duodenal contents. ${ }^{4}$ These showed in a series of tests with water and with o. I $M$ sodium chloride solution that the presence of the salt inhibited markedly the action toward ethyl butyrate in every case, but that toward triacetin either very slight inhibition or marked acceleration was shown. The probable presence of an esterase and a lipase in intestinal contents under different conditions was described in the tenth paper. It would appear from these results, that the esterase and the lipase present are affected differently by the salts, the action of the esterase being inhibited by the simple uni-univalent salts at all concentrations, that of the lipase being accelerated at certain concentrations and inhibited at other, higher, concentrations.

1 Supplied by the Baker Castor Oil Company, New York.

${ }^{2}$ Loc. cit.

3 This Journal, 35, 601 (1913).

$4 \mathrm{X}$ paper of this series, This Journal, 36, 1054 (1914). Cf. also the work of Terroine (Biochem. Z., 23, 404 (1910)) with animal pancreatic juice. 
Sodium sulfate exerted no apparent action on the activity of the castor bean preparation toward ethyl butyrate, but exerted marked acceleration toward triacetin. It is possible that here a retarding action of the sodium and accelerating action of the $\mathrm{SO}_{4}$ on the two enzymes exert their influences to produce the results observed.

The effect of drying and of heat on the activity of the ether extracted, air dried castor bean preparation was studied. The preparation was placed in a vacuum desiccator containing calcium chloride or phosphorus pentoxide for the required lengths of time, the loss in weight determined and the activity of $0.18 \mathrm{~g}$. portions tested toward ethyl butyrate and triacetin in $25 \mathrm{cc}$. $\mathrm{H}_{2} \mathrm{O}$ for $24 \mathrm{hrs}$, at $38-40^{\circ}$. Other portions were heated and tested similarly, and finally some portions were first dried in desiccators, then heated, and finally tested. The results are given in Table II.

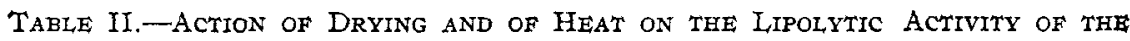
Castor Bean Preparation.

\begin{tabular}{|c|c|c|c|c|c|}
\hline \multirow[b]{2}{*}{ Troatment. } & \multirow[b]{2}{*}{$\begin{array}{l}\text { Grams } \\
\text { taken. }\end{array}$} & \multirow[b]{2}{*}{$\begin{array}{l}\text { Loss. } \\
\text { Grama. }\end{array}$} & \multirow[b]{2}{*}{$\begin{array}{l}\text { Loss. } \\
\text { Per cent }\end{array}$} & \multicolumn{2}{|c|}{ Activity. } \\
\hline & & & & $\overparen{\mathrm{Et} \mathrm{Bu}}$ & Triac. \\
\hline $\mathrm{CaCl}_{2}$ desiccator, 3 days. & 1.0034 & 0.0719 & 7.17 & I. 59 & 1.56 \\
\hline $\mathrm{P}_{2} \mathrm{O}_{5}$ & I. .0074 & 0.1055 & I0. 47 & . & $\cdot$ \\
\hline & & 0. 1067 & 10.59 & 1.70 & .70 \\
\hline roo- & I. .02 II & 0.0930 & 9.II & 0.31 & $0.6 \mathrm{I}$ \\
\hline $100^{\circ}$ & 2.5048 & 0.2573 & 10.27 & 0.68 & 0.95 \\
\hline ccator, 2 days & I.0299 & 0.0667 & 6.47 & & \\
\hline $2 \mathrm{da}$ & & 0.0719 & 6.98 & $\cdots$ & . \\
\hline $0-1 \times 0^{\circ}$ & . & 0.0988 & 9.59 & 0.13 & $0.4 \mathrm{I}$ \\
\hline $\mathrm{P}_{2} \mathrm{O}_{6}$ & 1.0033 & 0.1022 & 10.19 & $\cdots$ & $\cdots$ \\
\hline Then I00-110 & $\cdots$ & 0.1038 & 10.34 & 0.28 & 0.64 \\
\hline
\end{tabular}

The activity of the preparation did not decrease on drying in a vacuum desiccator over calcium chloride or phosphorus pentoxide. With the latter, considerably more moisture was taken out than with the former, as was to have been expected. On heating to $100-110^{\circ}$, although the loss in weight was not as great as in standing over phosphorus pentoxide, the activity was decreased very much. Also, first drying over calcium chloride to remove most of the moisture and then heating decreased the activity similarly. Drying over phosphorus pentoxide to remove practically all the moisture, and then heating, by which only $0.15 \%$ more was lost, decreased the activity just as much as if no preliminary drying had taken place. These results indicate that the inactivation due to heating the lipase is not connected with a simple loss of water or dehydration, but is doubtless due to some more deepseated chemical change.

The analysis of the castor bean preparation may be given here. The methods of analysis used were briefly as follows: Total ash was determined by careful heating and subsequent ignition of the material in a platinum dish, moistening with nitric acid and reignition until the ash 
was no longer dark colored. The residue was taken up with water and nitric acid, calcium sulfate precipitated by sulfuric acid and alcohol, and, in the filtrate from this precipitate magnesium and phosphorus were determined in separate aliquot parts, each as magnesium pyrophosphate. ${ }^{1}$ The analyses by the Neumann method were carried out by heating the material with concentrated sulfuric acid and addition of concentrated nitric acid until the mixture was colorless. After dilution, the calcium and magnesium were determined in the usual way, the phosphorus by precipitation with molybdate solution and weighing the precipitate $\left(\mathrm{NH}_{4}\right)_{3} \mathrm{PO}_{4}$. I $2 \mathrm{MoO}_{3}$ after drying at I IO-I $20^{\circ}$ in a Gooch crucible.

Castor Bean Preparation.-9.70\% moisture (100-110 ), I I.6\% N (Kjeldahl), $6.70 \%$ ash, $4.13 \% \mathrm{P}_{2} \mathrm{O}_{5}, 1.42 \% \mathrm{MgO}, 0.16 \% \mathrm{CaO}$ (Neumann method).

$7.42 \%$ ash in dry substance.

13.9\% $N$ in ash- and moisture-free substance.

\section{Esterase Material: Preparation and Properties.}

In extracting the castor bean preparation with water it was found best to use a large number of small portions instead of few portions and large amounts of material. The extraction was more satisfactory in this method of working, more homogeneous mixtures were obtained and the filtration through asbestos was much more rapid. In the following work, which was carried on from the preparative standpoint, $0.5 \mathrm{~g}$. preparation and $60 \mathrm{cc}$. water were used in each portion, and the extraction allowed to proceed for 24 hrs. since this length of time appeared to be sufficient to remove most, if not all, of the esterase. It was also found more convenient to centrifuge the extraction mixtures before filtering through asbestos, although this procedure was not essential.

The clear aqueous extracts contained the esterase or material with which the esterase was associated. $25 \mathrm{cc}$. of the extract required $0.20 \mathrm{cc}$. o.I $N \mathrm{NaOH}$ solution to be neutral toward phenolphthalein. Saturating the extract with $\left(\mathrm{NH}_{4}\right)_{2} \mathrm{SO}_{4}$ produced a flocculent precipitate, which, when dried on a porous plate, showed a small but appreciable activity, greater toward ethyl butyrate than toward triacetin under the standard conditions used. Owing to the presence of adsorbed ammonium sulfate, these titrations with alkali were carried out after the addition of neutralized formaldehyde solution. Precipitation of the aqueous extracts with other salts such as $\mathrm{NaF}, \mathrm{NaCl}, \mathrm{MgSO}_{4}$, or $\mathrm{HgCl}_{2}$ gave either small amounts of inactive material or turbidities which could not be filtered. The addition of alcohol or of acetone to these solutions also produced marked turbidities from which, however, no solid material could be obtained either by centrifuging or by filtration.

Active solid preparations containing the esterase could be obtained by first dialyzing the clear aqueous extracts from the castor bean preparation

${ }^{1}$ Cf. Abdețhalden, Handbuch der bioch. Arbeitsmeth., 6, 381 (1912). 
before attempting precipitation. These clear extracts became very turbid on dialysis and small amounts of solid matter separated. At the same time they became very nearly neutral in reaction toward phenolphthalein. The volume of the solutions increased $8-10 \%$ on $24 \mathrm{hrs}$. dialysis against running water in collodion bags. The activity of the neutral turbid dialyzed solution was less than that of the slightly acid undialyzed extract, but the addition of the amount of acetic acid to the former necessary to produce the same acidity as the latter resulted in very nearly the same activity. The turbid dialyzed solutions could also be filtered and the clear solutions showed the same activity as the turbid. To obtain these clear filtrates, the turbid solutions must be passed repeatedly through hardened filter paper. The following tests of the activities of these solutions and mixtures may be cited in this connection:

Clear aqueous extracts. - Tested $25 \mathrm{cc}$. portions (acidity equivalent to $0.20 \mathrm{cc}$. 0.1 $N \mathrm{NaOH}$ ), 24 hrs. Et Bu I.23; Triac. 0.48 .

Dialyzed this clear extract $18 \mathrm{hrs}$.- Very turbid. Tested $25 \mathrm{cc}$. portions (acidity equivalent to $0.08 \mathrm{cc}$. 0.I $N \mathrm{NaOH}$ ) after the addition of $0.12 \mathrm{cc}$. $0.1016 \mathrm{~N}$ acetic acid. Et Bu I.06; Triac. 0.35 .

Filtered the turbid dialyzed extract until clear.-Tested $25 \mathrm{cc}$. portions (acidity equivalent to $0.08 \mathrm{cc}$. $0.1 \mathrm{~N} \mathrm{NaOH}$ ) after the addition of $0.12 \mathrm{cc}$. $0.1016 \mathrm{~N}$ acetic acid. Et Bu 0.9I; Triac. 0.I8.

Clear aqueous extract.-Tested $25 \mathrm{cc}$. portions (acidity equivalent to $0.20 \mathrm{cc}$. 0.I $N \mathrm{NaOH}), 24$ hrs. Et Bu r.05; Triac. 0.56 .

Dialyzed 16 hrs., volume increased $8 \%$ - -Very turbid. Neutral. Tested 25 cc. portions. Et $\mathrm{Bu} 0.53$; Triac. 0.25 . Tested $30 \mathrm{cc}$. portions after addition of 0.20 cc. $0.1016 N$ acetic acid. Et Bu 0.96 ; Triac. 0.33 .

Filtered dialyzed solutions till clear.-Tested 25 ce. portions. Et Bu 0.53; Triac. 0.24 .

These results show clearly that the active esterase was contained in the clear neutral solution obtained after dialyzing and filtering the aqueous extracts of the castor bean preparation. The presence of small amounts of acid increased the activity of the esterase considerably, but its action was still very marked even without this added acid. The addition of dilute $\mathrm{Ba}(\mathrm{OH})_{2}$ solution to the turbid dialyzed solution until it was strongly alkaline cleared up the turbidity to a great extent. This appears to eliminate any appreciable quantities of phytin as one of the constituents of the solution.

The effect of dialyzing the clear aqueous extracts of the castor bean preparation for different lengths of time was studied in so far as any action was noticeable on the activity of the solutions. In Table III, the first column indicates the lengths of time the clear extracts of the castor bean preparation were dialyzed in collodion bags against running water having a temperature between $10^{\circ}$ and $15^{\circ}$. The second and third columns show the volumes of the solutions before and after dialysis. The fourth column gives the volumes of the solutions used in making the activity tests. These 
tests were made after filtering the turbid dialyzed solutions. The last four columns give the results of the activity tests made directly without the addition of acid. Under "Found" are given the results actually obtained, under "Cor." are given the results calculated from those "Found," to $25 \mathrm{cc}$. of original undialyzed solution. These corrected results give a truer measure of comparative activities. The analyses of the solid preparations obtained from these solutions will be given in Table IV in connection with some other analyses.

TABLe III.-The EfFect of Dialysis on the Activity of The Esterase.

\begin{tabular}{|c|c|c|c|c|c|c|c|}
\hline \multirow{3}{*}{$\begin{array}{c}\text { Time of } \\
\text { dialysis. } \\
\text { Hrs. }\end{array}$} & \multicolumn{2}{|c|}{ Volume. } & \multirow{3}{*}{$\begin{array}{l}\text { Cc. used } \\
\text { for } \\
\text { activity } \\
\text { tests. }\end{array}$} & \multicolumn{4}{|c|}{ Activities, 24 hrs. } \\
\hline & \multirow{2}{*}{$\begin{array}{c}\text { Before } \\
\text { dialysis. } \\
\text { Cc. }\end{array}$} & \multirow{2}{*}{$\begin{array}{c}\text { After } \\
\text { dialysis. } \\
\text { Cc. }\end{array}$} & & \multicolumn{2}{|c|}{ Et Bu. } & \multicolumn{2}{|c|}{ Triac. } \\
\hline & & & & Found. & Cor. & Found. & Cor. \\
\hline 5 & II 50 & 1200 & 25 & 0.77 & 0.80 & 0.27 & 0.28 \\
\hline 18 & 350 & 375 & 25 & 0.73 & $0.78\}$ & 0.24 & $0.26\}$ \\
\hline 20 & 900 & 960 & 25 & 0.59 & $0.63\}^{0.71}$ & 0.29 & $0.3 \mathrm{I}\}^{0 .}$ \\
\hline 66 & 650 & 720 & 25 & 0.44 & 0.49 & 0.18 & 0.20 \\
\hline 90 & 900 & 1000 & 25 & 0.34 & $0.38\}$ & 0.12 & 0.133 \\
\hline 93 & 800 & 840 & 25 & 0.33 & 0.355 & 0.23 & $0.24\}$ \\
\hline
\end{tabular}

These results show that the activity of the esterase decreased on continued dialysis, these decreases being very nearly proportional to the times. of dialysis.

The turbid dialyzed solution precipitated with alcohol gave a solid preparation which showed no activity. Precipitation with three volumes of acetone, standing over night, filtering, grinding repeatedly with fresh acetone, and drying in a vacuum desiccator gave active preparations. Some tests with these preparations, called $E_{I}$ for convenience, follow:

o.I g. EI, $50 \mathrm{cc}$. water, $0.50 \mathrm{cc}$. $0.1016 \mathrm{~N}$ acetic acid, 48 hours' test; Et Bu I.40. 0.02 g. EI, $50 \mathrm{cc} . \mathrm{H}_{2} \mathrm{O}, 48$ hours' test; different amounts $0.1016 \mathrm{~N}$ acetic acid.

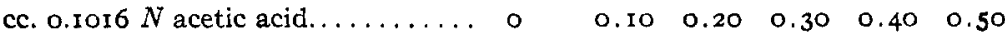

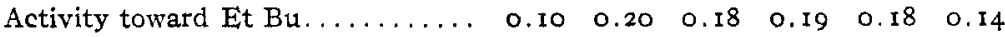

An esterase preparation, $E_{I I}$, was prepared from the clear filtrate from. the turbid dialyzed extract similarly by precipitation with acetone, filtering, grinding with fresh acetone and drying in a vacuum desiccator.

The activity of $E_{I I}$ is shown by the following result: $0.05 \mathrm{~g}$. $E_{\text {II }}, 25 \mathrm{cc}$. water, 0.20 cc. 0. IoI $6 N$ acetic acid, 24 hours' test; Et Bu 0.53, 'Triac. o.r3.

In preparing $E_{I I}$, it was found that, using apparently the same procedure and manipulation, at times solid material was obtained showing no. activity. The reasons for these differences are entirely unknown.

Attempts to prepare purer material by dissolving $E_{I}$ or $E_{I I}$ in water, filtering, dialyzing, filtering again, and precipitating with acetone gave solid preparations showing only small activity toward ethyl butyrate.

The castor bean preparation gave strong reactions for tyrosine (Folin's. reagent ${ }^{1}$ ), tryptophane (Hopkins-Cole test), aromatic group (Xantho-

1 J. Biol. Chem., 12, 239 (I912). 
proteic test) and carbohydrates (Molisch test). 5-10 mg. substance were used in these and the following tests. The esterase preparations $E_{I}$ and $E_{\text {II }}$ gave negative tests for carbohydrates, positive tests for tryptophane and aromatic groups, and very faintly positive for tyrosine. The redissolved and reprecipitated $\mathrm{E}_{\mathrm{I}}$ preparation gave negative tests for tyrosine and tryptophane, otherwise no change.

The results obtained in determining moisture, ash, and $\mathrm{P}_{2} \mathrm{O}_{5}$, in the different esterase preparations are given in Table IV.

TABle IV.-ANal,yses OF Esterase Preparations.

\begin{tabular}{|c|c|c|c|c|c|c|}
\hline Preparation. & $\begin{array}{l}\% \text { loss in } \\
3 \text { hrs at } \\
100-110^{\circ}\end{array}$ & $\begin{array}{c}\% \text { ni- } \\
\text { trogen. }\end{array}$ & $\%$ ash. & $\% \mathrm{P}_{2} \mathrm{O}_{6}$ & $\begin{array}{l}\% \\
\text { ash in } \\
\text { dried } \\
\text { subst. }\end{array}$ & $\begin{array}{c}\% \text { nitrogen } \\
\text { in ash and } \\
\text { moisture-free } \\
\text { substance. }\end{array}$ \\
\hline$E_{1} \ldots$ & 8.55 & 12.8 & 8.03 & 3.85 & 8.78 & 14.4 \\
\hline EII (5 hrs. dialysis) & 6.56 & 13.9 & 4.80 & 2.08 & $5 \cdot 14$ & $15 \cdot 7$ \\
\hline Err (20 hrs. dialysis) ........ & 8.38 & 14.2 & 4.26 & 1.43 & 4.65 & 16.3 \\
\hline II (66 hrs. dialysis) ........ & $7 \cdot 52$ & $\mathrm{I} 4.0$ & $4 \cdot 70$ & . & 5.08 & 15.9 \\
\hline II (9o hrs. dialysis).. & 7.80 & $13 \cdot 5$ & 4.62 & 0.85 & $5 . \infty$ & $15 \cdot 4$ \\
\hline I (reprecipitated). & $7 \cdot 37$ & I5.2 & I. 26 & 0.08 & I. 36 & 16.6 \\
\hline
\end{tabular}

The amount of nitrogen in the esterase preparations was considerably greater than in the original castor bean preparation, while the percentage of ash was less, except for $E_{\mathrm{I}}$. The percentage of nitrogen and the absence of carbohydrate reaction indicate that the preparation is mainly, if not entirely, protein in nature. The length of time of dialysis exerted no influence on the percentage of ash present, while with the nitrogen the differences in the different preparations showed no regularities and were probably accidental. The preparation $\mathrm{E}_{\mathrm{I}}$, obtained by precipitating the turbid dialyzed extract, contained more ash and less nitrogen than did the preparation $\mathrm{E}_{\mathrm{II}}$ obtained by precipitating the clear filtered dialyzed extract. The reprecipitated preparation showed less ash and more nitrogen than did any of the others, but this preparation was only slightly active. The only regularity between the activity and the composition appeared to be in the percentage of $\mathrm{P}_{2} \mathrm{O}_{5}$ present. For the series $\mathrm{E}_{\mathrm{II}}$ and times of dialysis and including the reprecipitated $\mathrm{E}_{\mathrm{I}}$, the greater the activity, the more $\mathrm{P}_{2} \mathrm{O}_{5}$ was present.

The existence of the water soluble esterase in castor beans is of interest in connection with some work on the hydrolysis of organic phosphorus compounds by enzymes published recently by R. H. A. Plimmer. ${ }^{1}$ Plimmer found that the enzyme glycerophosphatase, capable of hydrolyzing glycerophosphoric acid into glycerin and phosphoric acid, was present in extracts of intestinal mucosa, kidney, castor oil seeds, yeast, and bran, but not in pancreas or liver extracts. He considered that "the absence of the enzyme from the extracts of pancreas and liver, which were prepared specially for lipase, and the presence of the enzymes in the extracts of the intestine

${ }^{1}$ Biochem. J., 7, 43 (1913). 
and kidney, tissues not usually regarded as good sources of lipase, point to this enzyme being distinct from lipase. Proof of the difference of the enzymes is given by the experiment with castor oil seeds; lipase is insoluble in water but an aqueous solution contains glycerophosphatase." As far as castor beans are concerned, the work described in this paper shows. a soluble esterase to be present in them. In the course of this work, intestinal secretions and pancreatic juice and bile were tested for estersplitting enzymes, and it is significant that it was made extremely probable in the X Paper that an esterase existed in intestinal juice and a lipase in pancreatic juice and bile. Although the evidence is not direct or complete, it is likely that the esterase and glycerophosphatase, if not identical, exist together and may be detected in preparations from the same sources.

\section{Lipase Material: Preparation and Properties.}

The residues of the castor bean preparation, after extracting with water, contained the greater part of the lipase, active toward triacetin. Evidence obtained in the extraction experiments indicated that the waterinsoluble lipase was somewhat soluble in sodium chloride solutions. ${ }^{i}$ Some preliminary experiments on the water-insoluble lipase material with different salt solutions showed that sodium chloride was the most satisfactory salt to use and the further experiments were, therefore, carried out exclusively with it.

A number of extraction experiments with sodium chloride solutions of different concentrations were made. The results are given in Table V. The water-soluble esterase was first removed by extraction as described. The residues from these extractions were then combined and treated. with the requisite sodium chloride solution in the ratio of residues corresponding to one gram original castor bean preparation to roo $\mathrm{cc}$. salt solution. These were allowed to extract $24 \mathrm{hrs}$. at room temp., filtered clear through asbestos with suction, and the filtrates dialyzed 18 to 20 . hrs. against running water in collodion bags. White precipitates formed in the solutions in the bags as the salt was removed by dialysis. The removal of the sodium chloride was almost always complete in 18 hrs. The volumes of the solutions increased as a rule. After dialysis, aliquot portions of the mixtures (solutions + precipitates) were tested for activity in the usual way. Practically no activity toward ethyl butyrate was. found for any of the mixtures. With the triacetin tests, the activities found for the mixtures after dialysis were calculated for purposes of comparison to correspond to the amount of extracting solution obtained from the extraction of $0.2 \mathrm{~g}$. original castor bean preparation.

A number of sets of such experiments were carried out. In place of giving the details of these, only the mean values for the different concen-

${ }^{1}$ IX paper of this series, Loc. cit., p. Igr3. 
trations of salt solutions used will be given. The first row of Table $\mathrm{V}$ shows the concentration of salt solution; the second, the activity, multiplied by IOO, toward triacetin of the dialyzed mixture corresponding to $0.2 \mathrm{~g}$. castor bean preparation; and the third row the results taken from the smoothed curve obtained by plotting concentration of extracting salt solution against the observed activities of the mixtures, as given in the first and second rows.

TABle V.-Summary of Lipase Extraction Experiments with Sodium Chloride SOlutions OF Different CONCENTRations.

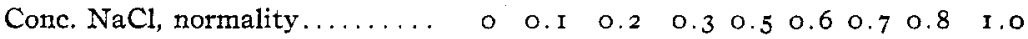

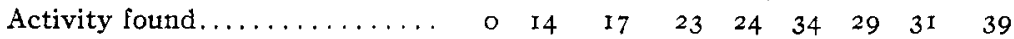

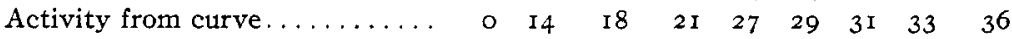

Conc. $\mathrm{NaCl}$, normality........ I. 25 I.50 I.75 2.0 2.53 .03 .54 .0 Saturated

Activity found............. $37 \quad 40 \quad \begin{array}{llllllll}39 & 37 & 37 & 32 & 31 & 22 & 14\end{array}$

Activity from curve......... $38 \quad \begin{array}{lllllllll}40 & 39 & 38 & 35 & 32 & 29 & 24 & 14\end{array}$

These results show that I.5 $N \mathrm{NaCl}$ solution extracted more active lipase than did any other concentration. In every salt extraction the removal of the salt by dialysis produced a precipitate in the solution. These mixtures, the activities of which were given in Table $V$, could be filtered readily. The filtrates showed no activity toward triacetin. The solid material must, therefore, contain the active lipase.

In the further work with this lipase, two extracting solutions were used; a saturated salt solution, giving the largest quantity of solid, the material obtained being designated $\mathrm{L}_{\mathrm{I}}$; and a I.5 $N$ salt solution, giving the most active extract, the material thus obtained being designated $L_{I I}$.

The castor bean residues after water and repeated salt extractions still showed marked activity toward triacetin, but very little toward ethyl butyrate. The continued treatment of the castor bean preparation with water and especially with salt solution undoubtedly modified the properties of some of the substances, colloidal and other, present originally in the preparation. The fact that the residues after the extractions described still show such marked activity, indicates that one or more other lipases are present which could not be obtained by the simple extractions described.

The effect of varying the times of dialysis of the salt extractions on the activity of the resulting mixtures was studied.

It was found that the activity of the lipase mixture was not diminished appreciably even after dialyzing continuously for six days. This behavior was in marked contrast to that of the esterase, the activity of which diminished fairly rapidly on continued dialysis. The difference in physical properties may account in part for this; the esterase remained in solution, while the lipase was precipitated out as the salt was removed and remained suspended in the solution. 
A number of attempts made to obtain the solid enzyme $I_{I}$ in active form from the dialyzed mixtures of the saturated salt solution failed.

More extended experiments were made with the $L_{\text {II }}$ mixture as obtained by dialyzing the I.5 $N$ salt extractions. First the activity of mixtures in water and in the salt solutions, suspended and dissolved, were compared. 800 cc. of I.5 $N$ salt extract were divided into two parts. $400 \mathrm{cc}$. were dialyzed for $48 \mathrm{hrs}$. against running water. The salt was removed completely and the volume increased to $565 \mathrm{cc}$. $50 \mathrm{cc}$. tested for $24 \mathrm{hrs}$. gave an activity of 0.62 toward triacetin. The remaining 400 cc. of the extract were allowed to stand at room temperature $48 \mathrm{hrs}$., the volume brought to $565 \mathrm{cc}$. with $1.5 N$ salt solution, $50 \mathrm{cc}$. portions tested for $24 \mathrm{hrs}$., giving an activity of 0.56 toward triacetin. Whether the material was dissolved in the salt solution or suspended in the aqueous solution appeared to be of small influence on its hydrolyzing action.

The $L_{\text {II }}$ solution mixture after being dialyzed, filtered, the residue washed thoroughly with water, and taken up with fresh water, showed very marked lipolytic action, indicating that the dialyzed solution contained no essential constituent (such as a coenzyme) of the lipase, but that the activity was all concentrated in the solid material $L_{I I I}$.

A number of tests with $50 \mathrm{cc}$. $\mathrm{L}_{\text {II }}$ water mixtures, $24 \mathrm{hrs}$., with added salts were made:

$\begin{array}{lccccc} & \mathrm{H}_{2} \mathrm{O} . & 0.1 \mathrm{M} \mathrm{NaCl} & 0.05 \mathrm{M} \mathrm{NaF} & 0.05 \mathrm{M} \mathrm{MgSO} & 0.002 \mathrm{M} \mathrm{MnSO} . \\ \text { Et Bu activity.... } & 0 . \mathrm{II} & 0.09 & 0.08 & 0.10 & 0.09 \\ \text { Triac. activity.... } & 0.92 & 0.95 & 0.48 & 0.89 & 0.97\end{array}$

The only marked influence of the salts was shown by the sodium fluoride, which inhibited the action strongly. The lack of either retarding or accelerating action of the sodium chloride is of interest, as well as the lack of accelerating action of the magnesium sulfate. Series of experiments in which the amount of water and the amount of triacetin were varied were also carried out. In the following experiments, different quantities of the $\mathrm{L}_{\mathrm{Ir}}$-water mixture and water were tested with $0.5 \mathrm{cc}$. triacetin for $24 \mathrm{hrs}$ :

$\begin{array}{lccccccc}\text { Cc. } \mathrm{L}_{\mathrm{II}} \text {-water mixture..... } & \text { 10 } & 20 & 40 & 60 & \text { 10 } & \text { 10 } & \text { 10 } \\ \text { Cc. water added } \ldots \ldots \ldots \ldots \ldots & 0 & 0 & 0 & 0 & 10 & 30 & 50 \\ \text { Activity } \ldots \ldots \ldots \ldots \ldots \ldots \ldots & 0.40 & 0.90 & 1.59 & 1.97 & 0.41 & 0.37 & 0.30\end{array}$

Except for the largest amount of $\mathrm{L}_{\mathrm{II}}$-water mixture used, the action was approximately proportional to the quantity of the $\mathrm{L}_{\text {II }}$ present. Similarly for the same amount of $\mathrm{L}_{\mathrm{II}}$-water mixture, addition of water exerted no influence on the reaction except for the largest quantity of water added.

With 5o cc. $\mathrm{L}_{\mathrm{II}}$-water mixture and different amounts of triacetin, 24 hrs. tests gave the following results: 


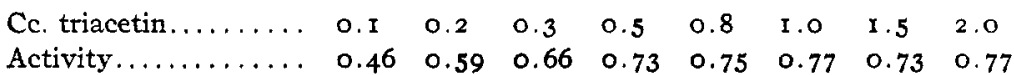

After a certain amount of triacetin, addition of still more did not increase the amount of action with the given quantity of lipase. The results of the last two series indicate that a definite quantity of lipase can only react with a certain quantity of triacetin in a given time. $0.5 \mathrm{cc}$. triacetin is the maximum amount with which $50 \mathrm{cc}$. $\mathrm{L}_{\mathrm{TI}}$-mixture could react, so that the result with $60 \mathrm{cc}$. $\mathrm{L}_{\mathrm{II}}$-mixture in the previous series was not proportional to the less amounts of lipase, because in the latter case an excess of triacetin was present, in the former, insufficient triacetin.

The precipitated $\mathrm{I}_{\text {II }}$ in the mixtures was readily dissolved by small amounts of dilute hydrochloric acid, sodium hydroxide, or glacial acetic acid, but not dilute acetic acid.

The solid $L_{\text {II }}$ material was prepared by filtering the precipitate from the dialyzed solutions on hardened paper, grinding with acetone in a mortar for some time and finally drying in a vacuum desiccator. The white powder obtained in this way was, however, only slightly active. The addition of small amounts of acetic acid or of sodium hydroxide did not increase the activity. This behavior is in marked contrast to that of the esterase which could be obtained active in solid form readily.

An attempt was made to obtain a more homogeneous material from the $\mathrm{L}_{\mathrm{II}}$, if possible. Two grams of $\mathrm{I}_{\mathrm{II}}$ were treated with roo cc. I.5 $\mathrm{N}$ sodium chloride solution. After ten minutes, when most of the solid had gone into solution, the mixture was filtered through hardened paper, the opalescent filtrate dialyzed against running water 20 hrs., a heavy white precipitate forming and the volume increasing to $300 \mathrm{cc}$. Practically no activity was shown by the mixture.

The analyses of the lipase preparations are given in Table VI.

Table VI.-Analyses of Lipase Preparations.

\begin{tabular}{|c|c|c|c|c|c|c|}
\hline Preparation. & $\begin{array}{l}\text { \% Loss in } \\
3 \text { hrs. at } \\
100-110^{\circ} .\end{array}$ & $\begin{array}{l}\% \mathrm{Ni}- \\
\text { trogen. }\end{array}$ & $\%$ Ash. & $\% \mathrm{P}_{2} \mathrm{O}_{5}$. & $\begin{array}{l}\% \text { Ash } \\
\text { in dried } \\
\text { subst. }\end{array}$ & $\begin{array}{l}\text { in ash } \\
\text { and mois- } \\
\text { twre-free } \\
\text { stubstatice. }\end{array}$ \\
\hline $\mathbf{L}_{\mathbf{I}} \ldots \ldots \ldots \ldots \ldots$ & 9.76 & $14 \cdot 3$ & 6.29 & 3.93 & 6.95 & 17.0 \\
\hline LII ( 24 hrs. dialysis). & 6.57 & $15 \cdot I$ & 4.04 & I. 50 & $4 \cdot 32$ & 16.9 \\
\hline In (44 hrs. dialysis) & $5 \cdot 37$ & $15 \cdot 3$ & 3.96 & I. 54 & 4.19 & 16.9 \\
\hline LII (67 hrs. dialysis... & 6.96 & 15.0 & 3.89 & I. 76 & $4 \cdot 18$ & 16.8 \\
\hline III (92 hrs. dialysis). & 8.26 & $14 . I$ & $5 \cdot 7 \mathrm{I}$ & I. 77 & 6.22 & 16.4 \\
\hline LII (I Is hrs. dialysis). & 8.00 & 14.5 & 4.80 & I, 85 & 5.22 & 36.6 \\
\hline LII (I 4 I hrs, dialysis)..... & 7.00 & I5.I & 3.60 & I. I4 & 3.87 & 16.9 \\
\hline $\mathrm{L}_{\mathrm{II}}$ (reprecipitated)........ & 7.59 & I6. I & 0.70 & 0.20 & 0.76 & 17.6 \\
\hline
\end{tabular}

The length of time of dialysis exerted no effect on the composition of the lipase preparation. The percentage of ash varied irregularly and is doubtless due to accidental causes. The only distinct features of the analyses are the facts that $I_{I}$, obtained with saturated salt solution, con- 
tained most ash, and that the redissolved and reprecipitated $\mathrm{L}_{\mathrm{II}}$ preparation contained less ash and more nitrogen than any of the other preparations.

Both the $L_{I}$ and $L_{\text {II }}$ preparations gave negative tests for carbohydrates (Molisch test) faintly positive for tyrosine (Folin reagent), distinctly positive for tryptophane (Hopkins-Cole test) and strongly positive for aromatic groups (Xanthoproteic test).

A characteristic property of the esterase of castor beans is its solubility in water, and of the lipase, its insolubility in water and solubility in salt solution. The hydrolytic power of these enzymes is doubtless associated with certain groups in the (presumably) protein molecule, and it is readily conceivable that these same groups might be present in protein molecules showing solubilities different than those of the castor bean preparation. It will be shown in a future paper, that the lipase of soy beans, which shows chemical properties similar in many respects to those of the lipase of castor beans, can be obtained dissolved in clear aqueous solution.

\section{Chemical Nature of Preparations.}

The principal forms in which nitrogen was present in the different preparations described in this paper were determined by Van Slyke's method. ${ }^{1}$ The microapparatus ${ }^{2}$ was used. About one gram of substance was hydrolyzed in each analysis. The final results are given in Table VII. The first set of results is for the castor bean preparation, the second for the esterase preparation $E_{I}$, the third for the lipase preparation $I_{\mathfrak{I}}$, the fourth for the lipase preparation $\mathrm{L}_{\mathrm{II}}$.

Table Vil.-Forms of Nitrogen in Preparations Expressedd as Percentages of Total Nitrogen.

\begin{tabular}{|c|c|c|c|c|}
\hline & $\begin{array}{l}\text { Castor bean } \\
\text { preparation. }\end{array}$ & $\underset{\mathrm{E}_{\mathrm{I}} \text { Esterase }}{\text { Es }}$ & $\underset{L_{\mathrm{I}} .}{\text { Lipase }}$ & $\begin{array}{l}\text { Lipase } \\
\text { I III. }\end{array}$ \\
\hline Ammonia nitrogen $\ldots \ldots \ldots \ldots$ & I2.1 & I 2.2 & 10.0 & 10.5 \\
\hline Melanine nitrogen,$\ldots \ldots \ldots \ldots \ldots \ldots$ & $3 \cdot 3$ & I. 5 & I. 7 & I. 8 \\
\hline Cystine nitrogen..... & 3.1 & 2.9 & 2.6 & 2.6 \\
\hline Arginine nitrogen. .... & 24.7 & 24.1 & $27 \cdot 1$ & 24.9 \\
\hline Histidine nitrogen............... & 6.2 & $4 \cdot 4$ & 6.5 & $4 \cdot 9$ \\
\hline Lysine nitrogen $\ldots \ldots \ldots \ldots \ldots \ldots$ & $4 \cdot 3$ & $3 \cdot 7$ & $2 \cdot 3$ & 3.9 \\
\hline Amino nitrogen of filtrate. . . . . . . & $49 \cdot 4$ & 49.0 & 53.6 & 51.8 \\
\hline Non-amino nitrogen of filtrate....... & $\cdots$ & 3.9 & $\cdots$ & 1.5 \\
\hline Tot & & 7 & 103.8 & IOI.9 \\
\hline
\end{tabular}

In carrying out the hydrolyses by heating with $20 \%$ hydrochloric acid as recommended by Van Slyke, it was observed that with the solid preparations, the substances were charred rapidly and separated considerable quantities of black carbonized material. An analysis was, therefore,

${ }^{1} \mathrm{~J}$. Biol. Chem., 10, I5 (1911); 12, 275 (1912).

2Ibid., I6, I21 (1913). 
made of an $\mathrm{L}_{\mathrm{II}}$-water mixture which had shown marked lipolytic action. Heating this mixture with the hydrochloric acid in the customary way resulted in a gradual darkening of the solution and deposition of very little black material. The results of this analysis are given in the column headed Lipase $\mathrm{L}_{\text {III }}$. The preparation of the solid $\mathrm{I}_{\text {III }}$ from the $\mathrm{L}_{\text {II }}$ mixture involved treatment with acetone and was accompanied by the inactivation of the material. It is possible that some chemical change was brought about in this treatment which manifested itself in the different behavior of the preparations on treating with hydrochloric acid, although no clew as to the nature of this change is evident at present.

Very little difference is shown in the relative proportions of the forms of nitrogen in the castor bean, esterase and lipase preparations. The nitrogen content of the ash-free esterase preparation $E_{\text {II }}$ ( 15.4 to $\left.16.3 \%\right)$ and of the ash-free lipase preparation $\mathrm{L}_{\mathrm{II}}(\mathrm{I} 6.4$ to $16.9 \%$ ) indicate that these consisted mainly, if not entirely, of protein material. The nitrogen distribution results confirm this conclusion in so far as it is shown that the forms in which the nitrogen exists in them are the same as those in which the nitrogen exists in other typical proteins, with differences in the amounts present in the different forms. The absence of carbohydrate substances (negative Molisch test), and of fats (method of preparation), also bears out the view that the preparations are essentially protein.

Sherman and Gettler ${ }^{1}$ have furnished fairly conclusive proof that their amylase preparations, obtained in a high state of purity and in very active form, were essentially protein in character. Every enzyme must naturally be considered independently as far as its chemical constitution is concerned, but it is a significant fact that up to the present time, protein material has been found in every enzyme preparation which has been investigated carefully and purified as far as possible. The amounts of protein found vary greatly. The invertase preparations of Nelson and Born, ${ }^{2}$ which appear to represent the products of greatest purity for this enzyme obtained up to the present, showed an average nitrogen content of about I. $3 \%$, while at the other extreme are the amylase preparations of Sherman and Gettler and the esterase and lipase preparations described here which appear to be entirely protein in character.

In considering whether the protein itself, or some part of it, can produce reactions which are characteristic of enzymes, it has been found possible to go somewhat further with the lipolytic actions than with the actions caused by other enzymes. Work in this laboratory has shown ${ }^{3}$ that simple aminoacids not only exert hydrolytic actions on esters, but that relatively

1 This Jodrnal, 36, I 790 (I913).

2 Ibid, 36, 396 (1914).

${ }^{3}$ II paper of this series, This Journal, 34, 828 (1912); M. L. Hamlin, VII and VIII Papers, Ibid., 35, 624, I897 (I913). 
simple differences in the structures of aminoacids caused changes in the rates of hydrolyses of simple esters not dependent upon the hydrogen ion concentration alone; in other words, that they act selectively on the esters. These actions, it is true, are comparatively small, but, if simple aminoacids can be shown to duplicate, even to less degree, the actions of different lipases, it is not only possible, but probable, that groupings in: complex proteins exist and may be found which will account for the enzymatic changes. There is no direct evidence that such groupings are the active factors, but the indirect evidence shows that the existence of such groupings is probable and would be sufficient to account for the reactions.

The writers wish to thank Mr. Morris Erenstoft for his efficient aid in carrying out the experimental work described in this paper.

\section{Summary.}

The extraction results described in a former paper were confirmed with a new castor bean preparation.

The action of the castor bean preparation on triacetin in the presenceof some neutral salts was described. The activity of the preparation was. tested after drying and heating under different conditions.

An esterase preparation, active toward ethyl butyrate, was separated by extraction with water, and its properties studied in solution and in the solid form. Its probable identity with glycerophosphatase was suggested.

A lipase preparation, active toward triacetin, was separated by extraction with $1.5 N$ sodium chloride solution, and its properties studied.

The forms of combination of the nitrogen in the preparations were determined. The probable protein nature of the esterase and lipase was discussed.

NEW YORK, N. Y.

\section{THE TOTAL AMINO NITROGEN IN THE SEEDLINGS OF THE ALASKA PEA.}

By Thos. G. Thompson. ${ }^{3}$

Received October 24, 1914.

While considerable attention appears to have been devoted to the occurrence of asparagin in plants, very little study seems to have been given to the total amount of amino and amide nitrogen that exists in plants at various stages of growth. Schulze ${ }^{2}$ published his ideas concerning the formation of amino acids in plants in 1898 . Later Scruti ${ }^{3}$ pointed out the importance played by phosphorus in the formation of acid amides and amino acids which go to build up the protein molecules. It is a gener-

${ }^{1}$ Acknowledgment is made to Dr. G. F. White who suggested and supervised this research.

${ }^{2} Z$. chim. Physiol., 24, 1898.

${ }^{3}$ Staz. sper. agrag. Ital., 4I, 456. 